\title{
Management of severe community-acquired pneumonia of children in developing and developed countries
}

\author{
Nicola Principi, Susanna Esposito
}

Department of Maternal and Paediatric Sciences, Università degli Studi di Milano,

Fondazione IRCCS Ca' Granda Ospedale Maggiore Policlinico, Milan, Italy

\section{Correspondence to}

Nicola Principi, Department of

Maternal and Paediatric

Sciences, Università degli Studi di Milano, Fondazione IRCCS Ca' Granda Ospedale Maggiore Policlinico, Via Commenda 9 , 20122 Milano, Italy: nicola.principi@unimi.it

Received 12 May 2010 Accepted 2 September 2010 Published Online First 21 October 2010

\section{ABSTRACT}

Childhood community-acquired pneumonia (CAP) is common, and recent data have shown that the number of children with severe CAP is increasing worldwide.

Regardless of geographical area, severe cases are those at the highest risk of hospitalisation, prolonged hospitalisation and death, and therefore require prompt identification and the most effective treatment in order to reduce CAP-related morbidity and mortality. This review evaluates the available data concerning the diagnosis and treatment of severe and/or complicated cases of paediatric CAP in developed and developing countries. It also underlines the fact that any evidence-based recommendations require more research in various areas, including the aetiology of severe cases and the reasons for the complications, the better definition of first-choice antibiotic treatment and when surgery may be useful, and the role of chest physiotherapy.

\section{INTRODUCTION}

Community-acquired pneumonia (CAP) is common among children all over the world, but its incidence and mortality rate are significantly higher in developing countries than in the industrialised world. ${ }^{1-3}$ It has been estimated that there are about 151 million new episodes a year among Third World children aged $<5$ years, leading to an incidence of 0.29 episodes per child-year and a mortality rate of $1.3-2.6 \%,{ }^{1}{ }^{2}$ or $>2$ million per year. In industrialised countries the total number of new episodes in the same age group is about 4 million (an incidence of 0.05 episodes per childyear), and the risk of mortality is extremely low in otherwise healthy children and relatively important only in subjects with severe chronic underlying diseases. $^{3} 4$

These differences are due to a number of factors. First, the incidence of risk factors such as malnutrition, crowding, low birth weight, HIV and the lack of measles and pneumococcal immunisation is much higher among children in developing countries. ${ }^{1-4}$ Second, they are more likely to be affected by other likely or possible risk factors such as zinc and vitamin A deficiency, poor maternal education and living in polluted areas. ${ }^{1-4}$ Finally, there are profound differences between developing and developed countries in the organisation and efficiency of their health systems. ${ }^{5}$

The aim of this review is to consider the available data concerning the diagnosis and treatment of severe cases of paediatric CAP. The data used in this review were identified by searching PubMed,
Medline, Current Contents and the reference lists of the relevant articles. The search terms were 'community-acquired pneumonia', 'severe pneumonia' and 'complicated pneumonia'. Only articles written in English and related to the paediatric population (aged 0-18 years) were considered. Given the large number of published papers, we have restricted ourselves to citing the most recent papers (2003-9) unless they were useful for background purposes. Since opportunistic agents may cause the majority of episodes in the immunocompromised host, we will not deal with pneumonia in children with impaired host defences.

\section{ASSESSING SEVERE CAP}

The estimated incidence of childhood hospitalisation due to CAP is $8.7 \%$ of all cases of CAP in developing countries ${ }^{4}$ and $0.3 \%$ in the developed world. ${ }^{67}$ However, it is not possible to compare the two because the criteria used to define CAP and its severity, and the prevalence of risk factors for the development of severe CAP, are very different (see table 1).

Given the limited availability of radiological equipment in the developing world, CAP is usually diagnosed only on the basis of clinical signs and symptoms. ${ }^{8}$ This often leads to an overestimate of the total number of cases because it is often confused with other respiratory diseases, mainly bronchiolitis. However, it may also be underestimated because the poor organisation of the health services in many developing countries means that many children with severe CAP are not admitted to hospital but die at home.

The fact that the severity of CAP is defined on the basis of clinical signs and symptoms can also lead to erroneous estimates because it has been shown that chest indrawing and increased respiratory rate have positive and negative predictive values as indicators of lung consolidation of only $45 \%$ and $83 \%$, ${ }^{9}$ and these percentages may be significantly lower in children aged $>36$ months. ${ }^{10}$ As shown in table 1 , developing countries use the WHO classification to define CAP severity, and severe CAP is diagnosed when, in addition to all the signs and symptoms used to diagnose lower respiratory tract involvement, a child shows lower chest wall indrawing, nasal flaring and (if young) grunting. ${ }^{11}$ Very severe $\mathrm{CAP}$ requires at least one more sign or symptom of respiratory, central nervous system or gastrointestinal involvement. It has been calculated that, on the basis of these criteria, more than $75 \%$ of the children hospitalised because of CAP have severe or very severe disease. ${ }^{12-15}$ 
Table 1 Criteria used in developing and developed countries to define the severity of community-acquired pneumonia (CAP)

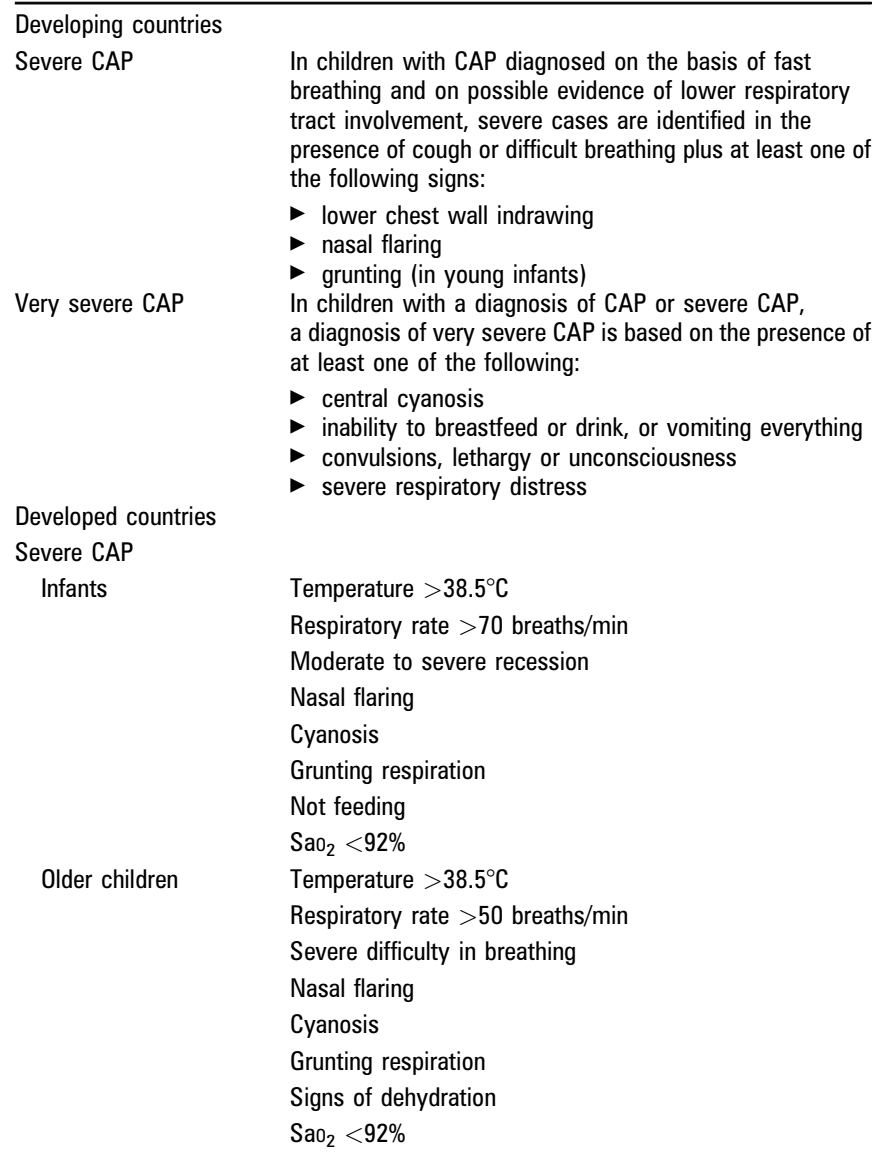

Adapted from the World Health Organization ${ }^{11}$ and the British Thoracic Society. ${ }^{7}$

$\mathrm{SaO}_{2}$, arterial oxygen saturation.

More reliable data regarding the incidence of severe and very severe CAP are probably collected in the developed world where most cases of CAP are confirmed by chest radiography. ${ }^{7}$ Furthermore, although there is no childhood score similar to that used in adults with CAP, ${ }^{16} 17$ experts agree that blood oxygenation is an essential factor for evaluating CAP severity and the best indicator of the need for hospitalisation, ${ }^{7}$ and the British Thoracic Society (BTS) guidelines for the management of children with CAP state that $<92 \%$ oxygen saturation is indicative of severe CAP. ${ }^{7}$ Using these criteria, a recent multicentre study carried out in 13 hospitals in north-east England by Clark et al found that $59 \%$ of children with radiologically-confirmed CAP aged $0-15$ years had severe disease and, when the analysis was restricted to infants, the incidence of severe CAP increased to $71 \%{ }^{18}$ These data confirm the previous findings of Tan et al ${ }^{19}$ and Michelow et al. ${ }^{20}$

Some authors have tried to use chest radiography to improve the definition of severe CAP but, although some studies indicate that lung consolidation is associated with greater clinical involvement, this is not confirmed by a global evaluation of all of the available data. ${ }^{21-24}$

\section{AETIOLOGY AND CAP SEVERITY}

It has long been known (mainly on the basis of lung puncture studies carried out in developing countries) that mild and moderate CAP is mainly caused by viruses, particularly in the first years of life, whereas most cases of severe CAP are caused by bacteria. $^{1-4}$
However, it has also been shown (in developing and developed countries) that influenza viruses and respiratory syncytial virus play a major role in causing severe and/or complicated CAP. ${ }^{25-27}$ The recent spread of the new influenza virus A/H1N1 has clearly shown that viral infection can cause CAP with a negative outcome in all age groups. ${ }^{28-30}$

Streptococcus pneumoniae, Haemophilus influenzae (including non-typeable strains) and Staphylococcus aureus are the most frequently cultured bacteria in severe paediatric cases, ${ }^{31-35}$ although some studies have also found that Streptococcus pyogenes and Gram-negative enteric bacteria are common. ${ }^{36} 37$ The importance of 'atypical' bacteria (Mycoplasma pneumoniae and Chlamydophila pneumoniae) in severe and/or complicated CAP has not been completely defined worldwide, largely because of difficulties in identifying them. ${ }^{21}$ However, recently published data indicate that a considerable number of children with CAP caused by atypical bacteria show a complicated course, mainly because of the presence of pleural effusion. ${ }^{38}$

The role played by different pathogens has significantly changed over recent years, particularly in the developed world. However, prevention of CAP is a major effort that is being carried out by different organisations such as the WHO also in developing countries. The widespread use of $H$ influenzae type $\mathrm{b}$ vaccine and, more recently, the heptavalent pneumococcal conjugate vaccine (PCV-7) has nearly eliminated CAP due to the first $^{39} 40$ and significantly reduced the number of cases due to the second pathogen. ${ }^{41-43}$ Considering the efficacy of these two vaccines, they have to be strongly recommended worldwide. $^{41-43}$ However, $S$ pneumoniae is still the most important aetiological agent of severe and/or complicated CAP throughout the world: ${ }^{4-46}$ pneumococcal serotypes 1 and 3 have been significantly more often associated with complicated than with non-complicated CAP, ${ }^{42} 4347-49$ and pneumococcal serotypes 5, 7F, 14, and 19A have frequently been associated with severe and/or complicated CAP. ${ }^{50} 51$

\section{TREATMENT}

In most cases it is not possible to identify the aetiology of CAP in clinical practice. ${ }^{1-3} 7182234$ Moreover, co-infections of bacteria and viruses are common worldwide and cannot be distinguished from infection due to a single pathogen. ${ }^{1-3} 7182234$ This means that antibiotic therapy is prescribed for all children with a strongly suspected or confirmed diagnosis of CAP, particularly if the clinical signs and symptoms are severe; however, there are differences in the therapeutic regimen usually used in developing and developed countries. ${ }^{1-3} 711162234$ In this regard, it should also be remembered that, in developing countries, some aetiologies are common (such as tuberculosis and malaria) and should also be considered for treatment in complicated cases ${ }^{2} 45$; this explains why antibiotics are almost always prescribed in patients with CAP.

\section{Antibiotic treatment in developing countries}

In developing countries the main goal of treatment is to reduce the risk of death as cheaply as possible. ${ }^{115253}$ Table 2 shows the antibiotic treatment suggested by the WHO for severe and very severe paediatric CAP cases diagnosed in the Third World. ${ }^{11}$ The recommended first-line drugs for severe cases are benzylpenicillin, amoxicillin and chloramphenicol, whereas ampicillin or amoxicillin plus gentamicin are recommended in the case of very severe CAP. ${ }^{11}$ The choice of an alternative regimen, the duration of therapy and hospitalisation, and the possibility of continuing antibiotic administration orally at home are all conditioned by 
Table 2 Antibiotic treatment of children with severe and very severe community-acquired pneumonia (CAP) according to the WHO guidelines recommended for developing countries

\begin{tabular}{ll}
\hline Severe CAP & Benzylpenicillin IM or IV for at least 3 days. When the child \\
improves, switch to oral amoxicillin for a total course of \\
treatment of 5 days \\
If the child does not improve within $48 \mathrm{~h}$ or deteriorates, look \\
for complications and treat accordingly (high-dose amoxicillin- \\
clavulanic acid with or without a macrolide). If there are no \\
apparent complications, switch to chloramphenicol $75 \mathrm{mg} / \mathrm{kg} /$ \\
day IM or IV until the child has improved. Then continue orally \\
for a total course of 10 days \\
Standard therapy: ampicillin IM or IV and gentamicin IM or IV \\
for 5 days; if the child responds well, complete treatment with \\
oral amoxicillin plus IM gentamicin for a further 5 days \\
Alternative therapies: (a) chloramphenicol IM or IV until the \\
child has improved and then continue orally for a total course of \\
10 days; (b) ceftriaxone IM or IV once daily for 10 days \\
Treatment in case the child does not improve after $48 \mathrm{~h}$ of \\
standard or alternative therapies: gentamicin IM or IV and \\
cloxacillin or dicloxacillin or flucloxacillin or oxacillin IM or IV. \\
When the child improves, continue cloxacillin (or dicloxacillin) \\
for a total course of 3 weeks
\end{tabular}

Adapted from the World Health Organization. ${ }^{11}$

IM, intramuscular; IV, intravenous.

the evolution of the disease, the development of complications and the presence of risk factors. ${ }^{11} 54$

It is clear that this approach causes a number of problems due to the risk of nosocomial morbidities and greater healthcare costs, which is why various studies have investigated whether it is possible to treat severe CAP orally at home without significantly increasing the number of treatment failures or the risks of complications and death. ${ }^{53}$ 55-59 Unfortunately, only a few of these are sufficiently adequate methodologically to allow firm conclusions. ${ }^{55-59}$ Nevertheless, despite their differences in terms of the antibiotics used and efficacy criteria, they all indicate that there is no significant difference between oral and parenteral therapy in the rates of treatment failure or clinical success at the end of therapy and the end of follow-up (table 3). However, these studies do not take into consideration the relative benefits and harms of oral antibiotics in children with CAP associated with bacterial confirmation, radiographic lobar consolidation or progression to empyema, which means that oral antibiotic therapy cannot be systematically prescribed in all cases of severe CAP. Consequently, the therapeutic approach suggested by the WHO remains the best compromise between the lowest risk of failure and the greatest simplicity of therapy.

One possible further simplification leading to a significant reduction in the duration of hospitalisation could theoretically be based on data concerning the predictors of a treatment response. In this regard, the proportion of children with pneumonia who fail to respond adequately to conventional antibiotic and supportive treatment varies from $9 \%$ to $21 \%$, regardless of the antibiotic used, ${ }^{60}$ and it has been demonstrated that data derived from a patient's history and first examination-such as younger age, previous use of antibiotics, breastfeeding, living in an overcrowded home, higher respiratory rate and immunisation status-are independent predictors of possible treatment failure. ${ }^{5761}$

When available, blood oxygen saturation offers substantial advantages in identifying possible treatment failures. Studies from Indonesia, Kenya, Zambia and Gambia have found that the risk of death is 1.4-4.6 times higher in children with hypoxia at baseline than in those without. ${ }^{53}$ 61-67 Chest radiography, which enables identification of the characteristics that correlate more with a bacterial or more with a viral aetiology, is often not available in developing countries. ${ }^{245}$ On the other hand, a pulse oximeter is significantly easier to use than chest radiographic equipment, less expensive, easier to calibrate and easier to maintain and repair. ${ }^{53}$ Consequently, its use (together with the consideration of clinical data) would seem to be the best way of deciding, after a brief period of observation, whether a child risks failure on oral antibiotic treatment or can be safely managed at home. Unlike in developed countries, fever and laboratory examinations are generally not used in developing countries for CAP assessment. ${ }^{2} 45$

\section{Antibiotic treatment in developed countries}

In industrialised countries the initial treatment of severe CAP includes hospitalisation and the intravenous administration of antibiotics. $^{7} 1622$ 68-70 The choice of antibiotic mainly depends on the patient's age, and a single drug active against the most

Table 3 Oral versus parenteral antibiotics for severe community-acquired pneumonia (CAP) in children

\begin{tabular}{llll}
\hline Author & Methods & Study population & Interventions \\
\hline Campbell, $1988^{56}$ & $\begin{array}{l}\text { Multicentre controlled } \\
\text { study }\end{array}$ & $\begin{array}{l}134 \text { children of mean age } \\
22 \text { months and WHO-defined } \\
\text { severe CAP in Gambia }\end{array}$ & $\begin{array}{l}\text { Randomly assigned to oral } \\
\text { co-trimoxazole for } 5 \text { days or } \\
\text { procaine penicillin + benzylpenicillin } \\
\text { one dose followed by oral ampicillin } \\
\text { for } 5 \text { days }\end{array}$ \\
Addo-Yobo, 2004 & $\begin{array}{l}\text { Multicentre randomised } \\
\text { open-label equivalency } \\
\text { trial }\end{array}$ & $\begin{array}{l}1702 \text { children aged 3-59 months } \\
\text { with WHO-defined severe CAP in } \\
\text { developing countries (Africa, Asia, } \\
\text { and South America) }\end{array}$ & $\begin{array}{l}\text { Randomly assigned to oral amoxicillin } \\
\text { or IV penicillin G, both groups for 48 h } \\
\text { followed by oral amoxicillin for } \\
\text { another } 5 \text { days }\end{array}$
\end{tabular}

Improved after 7 days: $66.6 \%$ in the oral only group and $60.3 \%$ in the combined group

Treatment failure after 14 days: $7.6 \%$ in the oral only group and $7.3 \%$ in the combined group

Treatment failure after $48 \mathrm{~h}: 18.6 \%$ in the amoxicillin group and $18.8 \%$ in the penicillin group

Treatment failure between $48 \mathrm{~h}$ and 5 days: $1.8 \%$ in the amoxicillin group and $2.2 \%$ in the penicillin group Treatment failure between 5 and 14 days: $2.2 \%$ in the amoxicillin group and $1.5 \%$ in the penicillin group

Treatment failure: $2.4 \%$ in the oral group and $5.8 \%$ in the IV group

Randomly assigned to oral amoxic changed to oral amoxicillin after a median of six IV doses for a total course of antibiotics of 7 days Randomly assigned to ambulatory group (oral amoxicillin for 5 days) or hospitalised group (IV ampicillin for $48 \mathrm{~h}$ followed by 3 days of oral amoxicillin) open-label equivalency with WHO-defined severe CAP trial in Pakistan
Cured: $90 \%$ in the ambulatory group and $88 \%$ in the hospitalised group Died: $0.09 \%$ in the ambulatory group and $(0.04 \%)$ in the hospitalised group 
probable infecting agent has long been suggested. $7162268-70$ However, the recent demonstration that atypical bacteria can play a role in causing severe CAP has led some experts to suggest using a combination of a beta-lactam and macrolide antibiotic in all children aged $>3$ months. ${ }^{16} 22$ Table 4 summarises the current therapeutic approach to severe CAP in developed countries recommended by a large group of experts. It appears clear that age is the most important factor to determine aetiology. Although viral aetiology plays a major role in children aged $<2$ years while in older children bacteria (especially atypical bacteria) are more common, the large overlap in clinical, laboratory and radiographic findings between the different aetiologies supports the systematic use of antibiotics in severe CAP. ${ }^{22}$

The global pandemic of antibiotic resistance of the isolated pathogens commonly found in children with respiratory disease has had a marginal impact on the antimicrobial management of severe and complicated paediatric CAP. ${ }^{22}$ This is because, although $S$ pneumoniae strains have progressively developed multiple resistance mechanisms over the last 20-30 years and resistant strains (including some with multidrug resistance) have spread to several regions of the world, ${ }^{71}{ }^{72}$ it has been found that the risk of failure after treatment with penicillins and cephalosporins is not significantly different from that usually found in adults and children with CAP due to antibiotic-sensitive $S$ pneumoniae strains. ${ }^{73-78}$ Moreover, in most of the cases of failure, it was difficult to define whether the negative result was a true bacteriological failure due to the resistance of the infecting organism or a clinical failure due to other concomitant factors. ${ }^{73-78}$ The success of treatment with beta-lactam antibiotics, even in the presence of resistant strains, can be easily explained on the basis of the pharmacokinetic and pharmacodynamic principles predicting probable clinical success. ${ }^{79} 80$

The question of the resistance of $S$ pneumoniae to macrolides is more important ${ }^{22}$ because the risk of the failure of macrolide monotherapy in cases of bacteraemic CAP has been clearly documented. $^{81} 82$ This explains why macrolide monotherapy is not suggested for the initial treatment of severe paediatric CAP and, when macrolides are prescribed, why they are always used in combination with beta-lactams in order to cover atypical bacteria (which have only rarely shown resistance to macrolides). ${ }^{22} 68$

Finally, in each antibiotic class the choice has to be restricted to the drug that is most active against the possible infecting agents and has the best tolerability and safety profile, the narrowest spectrum of activity and the lowest cost. ${ }^{1-3} 72234$ Once a clinical improvement has been demonstrated, patients who can tolerate oral medications and do not have diarrhoea should be switched to oral therapy in order to reduce patient discomfort, favour hospital discharge and limit healthcare costs. The total duration of treatment is usually 10-14 days. In the case of complications, broader spectrum antibiotics (eg, piperacillin plus a beta-lactam inhibitor or a carbapenem combined with vancomycin) are recommended for longer periods (3-6 weeks).

\section{TREATING COMPLICATIONS \\ Parapneumonic effusion}

The rates of parapneumonic effusion have been increasing in the USA and Europe over recent years, and it is now encountered in approximately $40 \%$ of all patients with bacterial pneumonias. ${ }^{19}{ }^{83-85}$ Some authors have suggested that the use of PCV-7 may be involved as a result of the so-called 'replacement phenomenon'19 41-43 83-85 - that is, by reducing the circulation of the strains included in the vaccine, PCV-7 favours diseases due to non-vaccine serotypes, including the serotypes 1 , $3,5,7 \mathrm{~F}$ and 19A that are frequently associated with empyema. However, this hypothesis requires confirmation because the effect of serotype replacement on invasive disease rates in children has so far been marginal, ${ }^{86} 87$ and it has been shown that the increasing incidence of infections due to serotypes such as $19 \mathrm{~A}$ is independent of the use of PCV-7. ${ }^{88}$ In most cases of empyema, fluid volume is minimal and the fluid is not contaminated and contains only marginal amounts of fibrin and cells. ${ }^{19}$ However, in the presence of bacteria (about $20-30 \%$ of cases), fluid volume tends to increase and its composition changes, with progression to the fibrinopurulent and

Table 4 Suggested drug treatments for severe community-acquired pneumonia (CAP) in developed countries

\begin{tabular}{|c|c|c|}
\hline Age group & Main bacterial causes & Antibiotic of choice \\
\hline Birth to 3 weeks & $\begin{array}{l}\text { Group B streptococci, Gram-negative } \\
\text { enteric bacteria, Listeria monocytogenes, } \\
\text { Staphylococcus aureus }\end{array}$ & $\begin{array}{l}\text { Administer IV ampicillin and IV gentamicin } \\
\text { or IV cefuroxime or IV cefotaxime (dose } \\
\text { based on gestational age or birth weight) } \\
\text { for } 10 \text { days* }\end{array}$ \\
\hline 4 weeks to 3 months & $\begin{array}{l}\text { Streptococcus pneumoniae, Chlamydia } \\
\text { trachomatis, Bordetella pertussis, } \\
\text { Staphylococcus aureus }\end{array}$ & $\begin{array}{l}\text { If patient is afebrile, give oral or parenteral } \\
\text { erythromycin or oral or parenteral } \\
\text { clarithromycin for } 10-14 \text { days or oral } \\
\text { azithromycin for } 3-5 \text { days } † \text {. If patient is } \\
\text { febrile, administer IV cefuroxime or IV } \\
\text { cefotaxime or IV ceftriaxone until fever } \\
\text { disappears, followed by oral cefuroxime } \\
\text { axetil or oral amoxicillin-clavulanic acid } \\
\text { for a total course of } 10-14 \text { days* }\end{array}$ \\
\hline 4 months to 18 years & $\begin{array}{l}\text { Streptococcus pneumoniae, Mycoplasma } \\
\text { pneumoniae, Haemophilus influenzae }\end{array}$ & $\begin{array}{l}\text { Administer IV cefuroxime or IV cefotaxime } \\
\text { or IV ceftriaxone until fever disappears, } \\
\text { followed by oral cefuroxime axetil or oral } \\
\text { amoxicillin-clavulanic acid for a total } \\
\text { course of } 10-14 \text { days combined with oral } \\
\text { or parenteral erythromycin or oral or } \\
\text { parenteral clarithromycin for } 10-14 \text { days } \\
\text { or oral azithromycin for } 3-5 \text { days* }\end{array}$ \\
\hline
\end{tabular}

${ }^{*}$ Staphylococcal pneumonia is unusual; however, if blood or pleural fluid cultures grow Staphylococcus aureus, oxacillin or, in areas where methicillin-resistant $S$ aureus is a reasonable possibility, vancomycin should be added.

†In infants aged $<6$ weeks, treatment with clarithromycin or azithromycin should be considered because there have been reports of hypertrophic pylotic stenosis in infants receiving erythromycin. IV, intravenous. 
organisation phase. ${ }^{11}$ In case of CAP, the fluid is caused by changes in local factors and is represented by exudate (ie, it differs from transudate because it is characterised by one of the following: ratio of pleural fluid protein to serum protein $>0.5$; ratio of pleural fluid lactate dehydrogenase $(\mathrm{LDH})$ to serum $\mathrm{LDH}$ $>0.6$; pleural fluid $\mathrm{LDH}>0.7$ times the normal upper limit for serum).

The aim of treating parapneumonic effusion is to sterilise the pleural fluid and restore normal lung function. Once again, the choice of antibiotic is different in developing and developed countries. The WHO recommends the administration of chloramphemicol $25 \mathrm{mg} / \mathrm{kg}$ intramuscularly or intravenously every $8 \mathrm{~h}$ until the child has improved, and then the same drug orally for a total of 4 weeks. ${ }^{11}$ In the case of documented infection due to $S$ aureus, the WHO suggests cloxacillin $50 \mathrm{mg} / \mathrm{kg}$ intramuscularly or intravenously every $6 \mathrm{~h}$ together with gentamicin $7.5 \mathrm{mg} / \mathrm{kg}$ intramuscularly or intravenously once a day until the child has improved, and then oral oxacillin four times a day for a total of 3 weeks. ${ }^{11}$

In the developed world, because $S$ pneumoniae is the most frequent cause of empyema, ${ }^{19} 838486$ primary therapy is based on high intravenous doses of an antibiotic capable of assuring good pneumococcal coverage. ${ }^{7} 1622$ As there is no correlation between the development of empyema and the presence of $S$ pneumoniae resistance to antibiotics, ${ }^{89}$ the recommended antibiotic is the same as that suggested for severe cases. In the case of necrotising pneumonia, progressive disease or underlying immunodeficiency, broader spectrum drugs combined with an antistaphylococcal antibiotic are indicated in very young children. The duration of administration has not been codified, but most authors suggest intravenous therapy for 1 week after the resolution of fever followed by oral therapy for a further 1-4 weeks. $^{90}$

Regardless of age, the drainage of pleural fluid is not indicated unless its ultrasonographically-detected volume exceeds $1 \mathrm{~cm} .{ }^{86} 90$ If the volume is higher, drainage is useful to confirm the diagnosis by excluding other causes of pleural effusion, define the quality of the fluid, identify the infecting organism and reduce respiratory symptoms, thus accelerating disease resolution. Theoretically, the fluid can be drained in four ways: thoracocentesis, by means of a chest tube (with or without fibrinolysis) or surgical debridement. ${ }^{90-93}$ A single tap can be used when ultrasound indicates that the fluid volume marginally exceeds $1 \mathrm{~cm}$ and lateral decubitus radiography shows that it is freely flowing in the pleural space,$^{90-93}$ but when the volume is greater or the fluid becomes loculated, it is necessary to use repeated taps or insert a drain. ${ }^{90-93}$ Although non-randomised studies have shown that the two procedures are comparable, many authors prefer drain insertion because repeated punctures are more traumatic. ${ }^{90-93}$

Fibrinolytic medication is advocated when the pleural fluid becomes organised. ${ }^{86909394}$ However, the efficacy of fibrinolytic agents is debated and the most recent data seem to suggest that they do not significantly reduce the duration of fever, chest tube drainage or hospitalisation, and that surgery may still be necessary regardless of the stage of the disease. ${ }^{95}$

Data concerning the efficacy of video-assisted thoracoscopic surgery (VATS) are also controversial. Avansino et al found that the patients who underwent primary surgery experienced less mortality and required shorter periods of hospitalisation, tube thoracostomy and antibiotic therapy. ${ }^{96}$ On the other hand, Sonnappa et al found that VATS and tube thoracostomy with intrapleural urokinase were substantially equivalent in terms of failure rates and median post-intervention hospitalisation. ${ }^{97}$
On the basis of these data, it seems that the stepwise algorithm for pleural empyema suggested by Proesmans and De Boeck can be considered acceptable. ${ }^{90}$ This considers antibiotics alone whenever the pleural fluid volume is $<1 \mathrm{~cm}$; if this is not the case, intercostal tube drainage should be used, with the addition of fibrinolytics when the fluid seems to be organised. VATS is only considered as a salvage procedure in cases where the previous therapies fail.

Finally, children with parapneumonic effusion should be carefully observed for signs and symptoms of haemodynamic deterioration due to pericardial effusion. ${ }^{90} 9899$ Although the amount of pericardial fluid is usually very small and does not give rise to symptoms, pericardiocentesis is sometimes needed.

\section{Necrotising pneumonia and pneumatoceles}

During the course of bacterial CAP, necrotising pneumonia and pneumatoceles develop as a result of localised bronchiolar and alveolar necrosis. ${ }^{100}$ Although bacteria such as $S$ pneumoniae, $H$ influenzae, Klebsiella pneumoniae and Escherichia coli may be involved, the main cause is $S$ aureus, ${ }^{100}$ which means that an intravenous antistaphylococcal drug should be immediately administered once the diagnosis has been made. The choice of drug depends on the incidence of the methicillin resistance of $S$ aureus in the area in which the case occurs: if this is more than $20 \%$, vancomycin should be used.

The duration of intravenous antibiotic administration has not been codified, but it is reasonable to assume that it should be continued until the child shows signs of improvement, and then be followed by oral administration for a total antibiotic course of at least 3 weeks.

Most pneumatoceles spontaneously disappear and the radiographic alterations within the first 2 months, although this may take as long as 6 months. Complicated cases should continue to be followed up, including those with more than $50 \%$ involvement of the hemithorax and severe atelectasis, and the development of broncopleural fistulae with tension. ${ }^{100}$ When these occur, image-guided catheter drainage is indicated and, if this fails, surgical excision is the only solution. ${ }^{100} 101$

\section{Lung abscesses}

Lung abscesses occur as a result of the acute destruction of the pulmonary parenchyma, usually due to bacteria gaining access from the oropharynx, ${ }^{102}{ }^{103}$ although less frequently they are caused by an underlying bronchial process, the evolution of CAP or a septic embolus.

Anaerobic bacteria (Prevotella, Fusobacterium, Peptostreptococcus and Bacteroides) are the most frequent agents recovered from lung abscesses and account for 70-90\% of all isolates. ${ }^{104} 105$ S aureus is most frequently found when there is associated empyema, ${ }^{106} 107$ and facultative pathogens include $\boldsymbol{\alpha}$-haemolytic streptococci, Enterobacteriaceae, S pyogenes and S pneumoniae. ${ }^{108} 109$

Evolution to a lung abscess is often insidious. Approximately half of such patients have cough and fever and produce sputum, and chest pain and haemoptysis may also occur. However, putrid breath is occasionally the sole or predominant manifestation. ${ }^{102} 103$ The diagnosis is based on the chest radiographic finding of an air-fluid level indicating a cavity at least $2 \mathrm{~cm}$ with a defined wall. ${ }^{110}$ However, chest x-rays are initially non-diagnostic in about one-fifth of cases. ${ }^{110}$ CT scanning is a useful means of defining the extent of the disease, any underlying anomalies and the presence of a foreign body. Ultrasonography may also be useful for follow-up purposes. ${ }^{110}$

The mainstay of treatment is prolonged antibiotic therapy. $^{111} 112$ Most experts advocate a 2-3-week course of 
parenteral antibiotics followed by a course of oral antibiotics to complete a total of 4-6 weeks. The chosen antibiotics should provide aerobic and anaerobic coverage (ie, a penicillinase-resistant agent active against $S$ aureus and clindamycin or piperacillin plus a beta-lactam inhibitor or meropenem). ${ }^{111} 112$ If Gramnegative bacteria are suspected or isolated, an aminoglycoside should be added. ${ }^{111} 112$

Between $80 \%$ and $90 \%$ of all lung abscesses resolve with the use of antibiotic therapy alone. Most children become asymptomatic within 7-10 days, although the fever may persist for as long as 3 weeks. ${ }^{111} 112$ In the case of severely ill patients or those who fail to improve after 7-10 days of appropriate antimicrobial therapy, surgical intervention should be considered. Minimally invasive and often CT-guided percutaneous aspiration techniques are increasingly being used, but drainage may also be necessary if the abscess is $>4 \mathrm{~cm}$ in diameter and causes a mediastinal shift or leads to ventilator dependency. ${ }^{113}$ In rare complicated cases, thoracotomy with lobectomy and/or decortications may be necessary. ${ }^{113}$

\section{SUPPORTIVE THERAPIES \\ Oxygen}

Oxygen administration is considered essential in the treatment of severe CAP in both developing and developed countries, although there are some minor differences in target oxygen saturation $\left(\mathrm{SaO}_{2}\right)$ levels. The WHO suggests giving oxygen to children with severe CAP and severely low chest indrawing or a respiratory rate of $\geq 70$ breaths/min, and to all children with very severe CAP. ${ }^{11}$ Oxygen administration is recommended until the signs of hypoxia disappear or, if pulse oximetry is available, until $\mathrm{SaO}_{2}$ remains stable at $>90 \%$. The BTS guidelines indicate oxygen administration in all cases of severe CAP and suggest maintaining $\mathrm{SaO}_{2}$ levels of $>92 \%{ }^{7}$

There are greater differences in the methods used to deliver oxygen because the WHO recommends nasal prongs or a nasal or nasopharyngeal catheter and stresses the fact that a face or head mask is not indicated, ${ }^{11}$ whereas the BTS guidelines suggest using nasal cannulae, a head box and face mask, while highlighting the fact that there is no strong evidence indicating that any of these methods is more effective than the others. ${ }^{7}$ On the other hand, feeding is easier with nasal cannulae, although they do not allow the delivery of oxygen flow rates of $>2 \mathrm{l} / \mathrm{min}$.

\section{Fluid therapy}

As children with severe CAP are usually unable to maintain their fluid intake because of breathlessness or fatigue, ${ }^{114-116}$ nasogastric or intravenous fluid therapy is mandatory. Nasogastric tube feeds can impair respiratory conditions in neonates and younger children with narrow nasal passages, ${ }^{114}$ so these and patients affected by vomiting should preferably undergo intravenous fluid infusion if possible. Fluid intake should be calculated taking into account possible dehydration and the greater liquid losses due to the increased respiratory rate and fever. However, fluid balance and serum electrolyte concentrations should be monitored daily because inappropriate antidiuretic hormone secretion is relatively common in severely ill children and, in such cases, the volume and type of fluid infusion should be carefully monitored. ${ }^{115} 116$

\section{Physiotherapy}

Chest physiotherapy is widely used in paediatric practice (particularly in the industrialised world) because it is thought to be beneficial in evacuating inflammatory exudates and tracheobronchial secretions, removing airway obstructions, reducing airway resistance, enhancing gas exchange and reducing the work of breathing. ${ }^{117} 118$ However, its real usefulness is debatable because there is no scientific evidence that it modifies the course of CAP, even in severe cases or in the presence of complications. ${ }^{119-122}$ Although not completely exhaustive because there are a number of types of chest physiotherapy whose efficacy may be different (ie, chest percussion and vibrations, the use of oscillating devices and the use positive expiratory pressure), these findings further support the recommendations of the BTS that chest physiotherapy should not be recommended in children with $\mathrm{CAP}^{7}$

\section{CONCLUSIONS}

Although severe CAP and the complications of bacterial CAP have become less frequent since the advent of the widespread use of effective antibiotics early in the course of infection and the possibility of preventing CAP by means of vaccines, they continue to contribute to paediatric morbidity, require invasive investigations and management, and prolong hospitalisation. The limited number of existing guidelines concerning the management of paediatric CAP only marginally consider severe and/or complicated cases, ${ }^{7} 6869$ and further international guidelines are urgently needed in both developing and developed countries. However, in order to develop evidence-based recommendations, more research is required in various areas such as the aetiology of severe cases and the reasons for the complications, the better definition of first- and second-line antibiotic therapy (including the doses and duration of parenteral and oral antibiotic treatment) and when surgery is really useful, clarification of the role of different types of chest physiotherapy depending on patient status and definition on how to follow up patients with the different types of complications. Finally, further efforts have to be made to prevent CAP so that a very high vaccination coverage against $H$ influenzae type $b$ as well as $S$ pneumoniae can be reached worldwide and the impact of the use of these vaccines can be monitored through active surveillance.

Funding This review was supported by a grant from the Italian Ministry of Health, Bando Giovani Ricercatori 2007

\section{Competing interests None.}

Provenance and peer review Not commissioned; externally peer reviewed.

\section{REFERENCES}

1. Ranganathan SC, Sonnappa S. Pneumonia and other respiratory infections. Pediatr Clin North Am 2009:56:135-56.

2. Chisti MJ, Tebruegge M, La Vincente $S$, et al. Pneumonia in severely malnourished children in developing countries-mortality risk, aetiology and validity of WHO clinical signs: a systematic review. Trop Med Int Health 2009;14:1173-89.

3. Atkinson M, Yanney M, Stephenson T, et al. Effective treatment strategies for paediatric community acquired pneumonia. Expert Opin Pharmacother 2007;8:1091-101.

4. Rudan I, Boschi-Pinto C, Biloglav Z, et al. Epidemiology and etiology of childhood pneumonia. Bull World Health Organ 2008;86:408-16.

5. Bryce J, Boschi-Pinto C, Shibuya K, et al. WHO estimates of the causes of death in children. Lancet 2005;365:1147-52.

6. MacIntyre C, Maclnryre P, Cagney M. Community-based estimates of incidence of risk factors for childhood pneumonia in Western Sydney. Epidemiol Infect 2003;131:1091-6.

7. British Thoracic Society of Standards of Care Committee. BTS guidelines for the management of community acquired pneumonia in childhood. Thorax 2002;57: i1-24.

8. Rudan I, El Arifeen S, Black RE, et al. Childhood pneumonia and diarrhoea: setting our priorities right. Lancet Infect Dis 2007:7:56-61.

9. Palafox M, Guiscafre $\mathrm{H}$, Reyes $\mathrm{H}$, et al. Diagnostic value of tachypnoea in pneumonia defined radiologically. Arch Dis Child 2000;82:41-5.

10. Cherian T, John TJ, Simoes E, et al. Evaluation of simple clinical signs for the diagnosis of lower respiratory tract infection. Lancet 1988;2:125-8. 
11. World Health Organization. Pocket Book of Hospital Care for Children. Guidelines for the Management of Common IIInesses with Limited Resources. WHO Press, 2005:72-81.

12. Tupasi TE, Velmonte MA, Sanvictores ME, et al. Determinants of morbidity and mortality due to acute respiratory infections: implications for interventions. J Infect Dis 1988:157:615-23.

13. Tupasi TE, Lucero MG, Magdangal DM, et al. Etiology of acute lower respiratory infections in children in Alabang, Metro Manila. Rev Infect Dis 1990;12(Suppl 8): S929-39.

14. Hazir T, Qazi S, Nisar YB, et al. Assessment and management of children aged 1-59 months presenting with wheeze, fast breathing, and/or lower chest indrawing: results of a multicentre descriptive study in Pakistan. Arch Dis Child 2004;89:1049-54.

15. Puumalainen T, Quiambao B, Abucejo-Ladesma E, et al. Clinical case review: a method to improve identification of true clinical and radiographic pneumonia in children meeting the World Health Organization definition for pneumonia. BMC Infect Dis 2008:8:95.

16. ERS Task Force Report. Guidelines for management of adult community-acquired lower respiratory tract infections. Eur Respir J 1998:11:986-91.

17. Mandell A, Wunderink RG, Anzueto A, et al. Infectious Diseases Society of America/American Thoracic Society consensus guidelines on the management of community-acquired pneumonia in adults. Clin Infect Dis 2007:44:527-72.

18. Clark JE, Hammal D, Spemver D, et al. Children with pneumonia: how do they present and how are they managed? Arch Dis Child 2007;92:394-8.

19. Tan TQ, Mason EO Jr, Wald E, et al. Clinical characteristics of children with complicated pneumonia caused by Streptococcus pneumoniae. Pediatrics 2002;110:1-6.

20. Michelow IC, Olsen $\mathrm{K}$, Lozano J, et al. Epidemiology and clinical characteristics of community-acquired pneumonia in hospitalized children. Pediatrics 2004;113:701-7.

21. Principi N, Esposito S. Emerging role of Mycoplasma pneumoniae and Chlamydia pneumoniae in paediatric respiratory tract infections. Lancet Infect Dis 2001;1:334-44.

22. Esposito S, Principi N. Emerging resistance to antibiotics against respiratory bacteria: impact on therapy of community-acquired pneumonia in children. Drug Res Up 2002;5:73-87.

23. Grafakou 0, Moustaki M, Tsolia $\mathrm{M}$, et al. Can chest $\mathrm{X}$-ray predict pneumonia severity? Pediatr Pulmonol 2004;38:465-9.

24. Key VK, Araùjo-Neto CA, Nascimento-Carvalho CM. Severity of childhood community-acquired pneumonia and chest radiographic findings. Pediatr Pulmonol 2009;44:249-52

25. Finelli L, Fiore A, Dhara R, et al. Influenza-associated pediatric mortality in the United States: increase of Staphylococcus aureus coinfection. Pediatrics 2008; 122:805-11.

26. Esposito S, Marchisio P, Principi N. The global state of influenza in children. Pediatr Infect Dis J 2008;27(Suppl 11):S149-53.

27. Shann F, Gratten M, Germer S, et al. Aetiology of pneumonia in children in Goroka Hospital, Papua New Guinea. Lancet 1984;2:537-41.

28. Chowell G, Bertozzi SM, Colchero MA, et al. Severe respiratory disease concurrent with the circulation of H1N1 influenza. N Engl J Med 2009;361:674-9.

29. Perez-Padilla R, de la Rosa-Zamboni D, Ponce de Leon S, et al. Pneumonia and respiratory failure from swine-origin influenza $\mathrm{A}$ (H1N1) in Mexico. N Engl J Med 2009;361:680-9

30. Lister $\mathbf{P}$, Reynolds F, Parslow $R$, et al. Swine-origin influenza virus H1N1, seasonal influenza virus H1N1, and critical illness in children. Lancet 2009;374:605-7.

31. Jansen AG, Sanders EA, Hoes AW, et al. Influenza- and respiratory syncytial virusassociated mortality and hospitalizations. Eur Respir J 2007;30:1158-66.

32. Falade AG, Mulholland EK, Adegbola RA, et al. Bacterial isolates from blood and lung aspirate cultures in Gambian children with lobar pneumonia. Ann Trop Paediatr 1997; 17:315-19

33. Forgie IM, O'Neill KP, Lloyd-Evans N, et al. Etiology of acute lower respiratory tract infections in Gambian children. II. Acute lower respiratory tract infection in children ages one to nine years presenting at the hospital. Pediatr Infect Dis $J$ 1991;10:42-7.

34. McCracken GH Jr. Diagnosis and management of pneumonia in children. Pediatr Infect Dis J 2000;19:924-8.

35. Vuori-Holopainen E, Salo E, Saxén $\mathrm{H}$, et al. Etiologic diagnosis of childhood pneumonia by use of transthoracic needle aspiration and modern microbiological methods. Clin Infect Dis 2002;34:583-90.

36. Mimica I, Donoso E, Howard JE, et al. Lung puncture in the etiological diagnosis of pneumonia: a study of 543 infants and children. Am J Dis Child 1971;122:278-82.

37. Klein J0. Diagnostic lung puncture in the pneumonia of infants and children. Pediatrics 1969;44:486-92.

38. Esposito S, Bosis S, Cavagna R, et al. Characteristics of Streptococcus pneumoniae and atypical bacterial infections in children $2-5$ years of age with community-acquired pneumonia. Clin Infect Dis 2002;35:1345-52.

39. Gessner BD, Sutanto A, Linehan $M$, et al. Incidence of vaccine-preventable Haemophilus influenzae type B pneumonia and meningitis in Indonesian children: hamlet-randomised vaccine-probe trial. Lancet 2005;365:43-52.

40. Watt JP, Wolfson LJ, O'Brien KL, et al. Burden of disease caused by Haemophilus influenzae type $b$ in children younger than 5 years: global estimates. Lancet 2009; 374:903-11.
41. Grijalva CG, Nuorti JP, Arbogast PG. Decline in pneumonia admissions after routine childhood immunisation with pneumococcal conjugate vaccine in the USA: a timeseries analysis. Lancet 2007;369:1179-86.

42. O'Brien KL, Wolfson LJ, Watt JP, et al. Burden of disease caused by Streptococcus pneumoniae in children younger than 5 years: global estimates. Lancet 2009; 374:893-902.

43. Van der Poll T, Opal SM. Pathogenesis, treatment, and prevention of pneumococcal pneumonia. Lancet 2009;374:1543-56.

44. Chiang WC, Teoh $\mathrm{OH}$, Chong $\mathrm{CY}$, et al. Epidemiological, clinical characteristics and antimicrobial resistance patterns of community-acquired pneumonia in 1702 hospitalized children in Singapore. Respirology 2007;12:254-61.

45. Wexler ID, Knoll S, Picard E, et al. Clinical characteristics and outcome of complicated pneumococcal pneumonia in a pediatric population. Pediatr Pulmonol 2006;41:726-34.

46. Cevey-Macherel M, Galetto-Lacour A, Gervaix A, et al. Etiology of communityacquired pneumonia in hospitalized children based on WHO clinical guidelines. Eur $J$ Pediatr 2009;168:1429-36

47. Hausdorff WP, Feikin DR, Klugman KP. Epidemiological differences among pneumococcal serotypes. Lancet Infect Dis 2005;5:83-93.

48. Byington CL, Korgenski K, Daly J, et al. Impact of pneumococcal conjugate vaccine on pneumococcal parapneumonic empyema. Pediatr Infect Dis J 2006;25:250-4.

49. Fletcher $\mathbf{M}$, Leeming J, Cartwright $\mathrm{K}$, et al. Childhood empyema: limited potentia impact of 7-valent pneumococcal conjugate vaccine. Pediatr Infect Dis $J$ 2006;25:559-60.

50. De Schutter ID, Malfroot A, Piérard D, et al. Pneumococcal serogroups and serotypes in severe pneumococcal pneumonia in Belgian children: theoretical coverage of the 7-valent and 9-valent pneumococcal conjugate vaccine. Pediatr Pulmonol 2006:41:765-70.

51. Bender JM, Ampofo K, Korgenski K, et al. Pneumococcal necrotizing pneumonia in Utah: does serotype matter? Clin Infect Dis 2008;46:1346-52.

52. Arifeen SE, Hoque DM, Akter T, et al. Effect of the integrated management of childhood illness strategy on childhood mortality and nutrition in a rural area of Bangladesh: a cluster randomised trial. Lancet 2009;374:393-403.

53. Subhi R, Adamson M, Campbell $\mathrm{H}$, et al. The prevalence of hypoxaemia among ill children in developing countries: a systematic review. Lancet Infect Dis 2009:9:219-27.

54. Grant GB, Campbell H, Dowell SF, et al. Recommendations for treatment of childhood non-severe pneumonia. Lancet Infect Dis 2009;9:185-96.

55. Rojas MX, Granados Rugeles C. Oral antibiotics versus parenteral antibiotics for severe pneumonia in children. Cochrane Database Syst Rev 2006;(2):CD004979.

56. Campbell H, Byass $\mathrm{P}$, Forgie IM, et al. Trial of co-trimoxazole versus procaine penicillin with ampicillin in treatment of community-acquired pneumonia in young Gambian children. Lancet 1988;2:1182-4.

57. Addo-Yobo E, Chisaka N, Hassan M, et al. Oral amoxicillin versus injectable oenicillin for severe pneumonia in children aged 3 to 50 months: a randomized multicentre equivalency study. Lancet 2004;364:1141-8.

58. Atkinson M, Lakhanpaul M, Smyth $\mathrm{A}$, et al. Comparison of oral amoxicillin and intravenous benzyl penicillin for community-acquired pneumonia in children (PIVOT trial): a multicentre pragmatic randomized controlled equivalence trial. Thorax 2007:62:1102-6.

59. Hazir T, Fox LM, Nisar YB, et al. Ambulatory short-course high-dose oral amoxicillin for treatment of severe pneumonia in children: a randomized equivalency trial. Lancet 2008:371:49-56.

60. Mamtani M, Patel A, Hibberd PL, et al. A clinical tool to predict failed response to therapy in children with severe pneumonia. Pediatr Pulmonol 2009; 44:379-86.

61. Tiewsoh K, Lodha R, Pandey RM, et al. Factors determining the outcome of children hospitalized with severe pneumonia. BMC Pediatr 2009:9:15.

62. Djelantik IG, Gessner BD, Sutanto A, et al. Case fatality proportion and predictive factors for mortality among children hospitalized for severe pneumonia in a rural developing country setting. J Trop Pediatr 2003:49:327-32.

63. Onyango FE, Steinhoff MC, Wafula EM, et al. Hypoxaemia in young Kenyan children with acute lower respiratory infection. BMJ 1993;306:612-15.

64. Smyth A, Charty H, Hart CA. Clinical predictors of hypoxaemia in children with pneumonia. Ann Trop Paediatr 1988;18:31-40.

65. Usen S, Weber M, Mulholland $\mathrm{K}$, et al. Clinical predictors of hypoxaemia in Gambian children with acute lower respiratory tract infection: prospective cohort study. BMJ 1999;318:86-91.

66. Fu LY, Ruthazer R, Wilson I, et al. Brief hospitalization and pulse oximetry for predicting amoxicillin treatment failure in children with severe pneumonia. Pediatrics 2006;118: $1822-30$

67. Patel A, Mamtani N, Hibberd PM, et al. Value of chest radiography in predicting treatment response in children aged 3-59 months with severe pneumonia. Int $J$ Tuberc Lung Dis 2008;12:1320-6.

68. McIntosh K. Community acquired pneumonia in children. N Engl J Med 2002; $346: 429-37$

69. Jadavji T, Law B, Lebel M, et al. A practical guide for the diagnosis and treatment of pediatric pneumonia. Can Med Assoc J 1997;156:S703-11.

70. Hale K, Isaacs D. Antibiotics in childhood pneumonia. Paediatr Respir Rev 2006:7:145-51.

71. Finch R. Bacterial resistance: the clinical challenge. Clin Microbiol Infect 2002;8 (Suppl 3):21-32. 
72. Felmingham D, Feldman C, Hrynicwicz W, et al. Surveillance of resistance of bacteria causing community-acquired respiratory tract infections. Clin Microbiol Infect 2002;8(Suppl 2):12-42.

73. Feldman C. Clinical relevance of antimicrobial resistance in the management of pneumococcal community-acquired pneumonia. J Lab Clin Med 2004;143:269-83.

74. Tan RO, Mason EO Jr, Barson WJ, et al. Clinical characteristics and outcome of children with pneumonia attributable to penicillin-susceptible and penicillinnonsusceptible Streptococcus pneumoniae. Pediatrics 1998;102:1369-75.

75. Choi EH, Lee HJ. Clinical outcome of invasive infections by penicillin-resistant Streptococcus pneumoniae in Korean children. Clin Infect Dis 1998;26:1346-54.

76. Friedland IR. Comparison of the response to antimicrobial therapy of penicillinresistant and penicillin-susceptible pneumococcal disease. Pediatr Infect Dis J 1995; 14:885-90

77. Cardoso MR, Nascimento-Carvalho CM, Ferrero F, et al. Penicillin-resistant pneumococcus and risk of treatment failure in pneumonia. Arch Dis Child 2008;93:221-5.

78. Nascimento-Carvalho CM, Cardoso MR, Brandileone MC, et al. Pencillin/ ampicillin efficacy among children with severe pneumonia due to penicillin resistant pneumococcus (MIC $=4 \mu \mathrm{g} / \mathrm{mL}$ ). J Med Microbiol 2009;58:1390-2.

79. Craig WA. Pharmacokinetic/pharmacodynamic parameters: rationale for antibacterial dosing of mice and men. Clin Infect Dis 1998;26:1-12.

80. Bryan CS, Talwani E, Stinson MS. Penicillin dosing for pneumococcal pneumonia. Chest 1997:112:1657-64.

81. Pihlajamaki M, Kotilainen $P$, Kaurila $T$, et al. Macrolide-resistant Streptococcus pneumoniae and use of antimicrobial agents. Clin Infect Dis 2001;33:483-8.

82. Lonks JR, Garau J, Gomez L, et al. Failure of macrolide antibiotic treatment in patients with bacteremia due to erythromycin-resistant Streptococcus pneumoniae. Clin Infect Dis 2002:35:556-64.

83. Hausdorff WP. The roles of pneumococcal serotypes 1 and 5 in paediatric invasive disease. Vaccine 2007;25:2406-12

84. Hendrickson DJ, Blumberg DA, Joad JP, et al. Five-fold increase in pediatric parapneumonic empyema since introduction of pneumococcal conjugate vaccine. Pediatr Infect Dis J 2008:27:1030-32.

85. Gupta R, Crowley S. Increasing paediatric empyema admissions. Thorax 2006;61:179-81

86. Hilliard TN, Henderson AJ, Langton Hewer SC. Management of parapneumonic effusion and empyema. Arch Dis Child 2003;88:915-17.

87. Hicks LA, Harrison LH, Flannery B, et al. Incidence of pneumococcal disease due to non-pneumococcal conjugate vaccine (PCV-7) serotypes in the United State during the era of widespread PCV-7 vaccination, 1998-2004. J Infect Dis 2007; 196:1346-54

88. Choi EH, Kim SH, Eun BW, et al. Streptococcus pneumoniae serotype 19 A in children, South Korea. Emerg Infect Dis 2008;14:275-81.

89. Eltringham G, Kearns A, Freeman R, et al. Culture-negative childhood empyema is usually due to penicillin sensitive Streptococcus pneumoniae capsular serotype 1. J Clin Microbiol 2003;41:521-2.

90. Proesmans M, De Boeck K. Clinical practice: treatment of childhood empyema. Eur J Pediatr 2009;168:639-45.

91. Mitri RK, Brown SD, Zurakowski D, et al. Outcomes of primary image-guided drainage of parapneumonic effusion in children. Pediatrics 2002;110:37-43.

92. Balfour-Lynn IM, Abrahamson E, Cihen G, et al. BTS guidelines for the management of pleural infection in children. Thorax 2005;60(Suppl 1):11-21

93. Maskell NA, Davies CW, Nunn AJ, et al. First multicenter intrapleural sepsis trial (MISTI) group. UK controlled trial of intrapleural streptokinase for pleural infection. N Engl J Med 2005;352:865-74

94. Yao CT, Wu JM, Liu CC, et al. Treatment of complicated parapneumonic pleural effusion with intrapleural streptokinase in children. Chest 2004;125:566-71.

95. Aydigan N, Aydigan A, Ozcan A, et al. Intrapleural streptokinase treatment in children with empyema. Eur J Pediatr 2008;167:739-44.
96. Avansino JR, Goldman B, Sawin RS, et al. Primary operative versus nonoperative therapy for pediatric empyema: a meta-analysis. Pediatrics 2005;115:1652-9.

97. Sonnappa S, Cohen G, Owens CM, et al. Comparison of urokinase and videoassisted thoracoscopic surgery for treatment of childhood empyema. Am J Respir Crit Care Med 2006:174:221-7.

98. Kishk YT, Abou-Elmaqd A, Abdel-Wahab AM. Identification of cardiovascular abnormalities in children with empyema thoracis by two-dimensional and Doppler echocardiography. Chest 1993:104:405-10.

99. Roberts JE, Bezack BJ, Winger DI, et al. Association between parapneumonic effusion and pericardial effusion in a pediatric cohort. Pediatrics 2008;122: e1231-5.

100. İmamoğlu M, Çay $A$, KoȘucu $P$, et al. Pneumatoceles in postpneumonic empyema: an algorithmic approach. J Pediatr Surg 2005;40:111-17.

101. Puligandla PS, Laberge JM. Respiratory infections: pneumonia, lung abscess, and empyema. Semin Pediatr Surg 2008;17:42-52.

102. Patradoon-Ho P, Fitzgerlad DA. Lung abscess in children. Paediatr Respir Rev 2007:8:77-84.

103. Al-Saleh S, Grasemann H, Cox P. Necrotizing pneumonia complicated by early and late pneumatoceles. Can Respir J 2008;15:129-32.

104. Yen CC, Tang RB, Chen SJ, et al. Pediatric lung abscess: a retrospective review of 23 cases. J Microbiol Immunol Infect 2004;37:45-9.

105. May ML, Robson J. Microbiological diagnosis procedures in respiratory infections: suppurative lung disease. Paediatr Respir Rev 2007;8:185-93.

106. Hidron Al, Low CE, Honig EG, et al. Emergence of community-acquired methicillinresistant Staphylococcus aureus strain USA300 as a cause of necrotizing community-onset pneumonia. Lancet Infect Dis 2009;9:384-92

107. Thomas B, Pugalenthi A, Chilvers M. Pleuropulmonary complications of PVLpositive Staphylococcus aureus infection in children. Acta Paediatr 2009;98:1372-5.

108. Hsieh YC, Hsiao $\mathrm{CH}$, Tsao PN, et al. Necrotizing pneumococcal pneumonia in children: the role of pulmonary gangrene. Pediatr Pulmonol 2006;41:623-9.

109. Kalaskar AS, Heresi GP, Wanger A, et al. Severe necrotizing pneumonia in children, Houston, Texas, USA. Emerg Infect Dis 2009;15:1696-8.

110. Hogan MJ, Coley BD. Interventional radiology treatment of empyema and lung abscesses. Paediatr Respir Rev 2008;9:77-84.

111. Principi N, Esposito S. Paediatric community-acquired pneumonia: current concepts in pharmacological control. Expert Opin Pharmacother 2003:4:761-77.

112. Ramphul N, Eastham KM, Freeman $\mathrm{R}$, et al. Cavitatory lung disease complicating empyema in children. Pediatr Pulmonol 2006;41:750-3.

113. Yunus M. CT guided transthoracic catheter drainage of intrapulmonary abscess. J Pak Med Assoc 2009:59:703-9.

114. Sporik R. Why block a small hole? The adverse effect of nasogastric tubes. Arch Dis Child 1994;11:393-4.

115. Dhawan A, Narang A, Singhi S. Hyponatraemia and the inappropriate ADH syndrome in pneumonia. Ann Trop Paediatr 1992;12:455-62

116. Haviv M, Haver $\mathrm{E}$, Lichtstein $\mathrm{D}$, et al. Atrial natriuretic peptide in children with pneumonia. Pediatr Pulmonol 2005;40:306-9.

117. Balachandran A, Shivbalan S, Thangavelu S. Chest physiotherapy in pediatric practice. Indian Pediatr 2005:42:559-68.

118. Wallis C, Prasad A. Who needs physiotherapy? Moving from anecdote to evidence. Arch Dis Child 1999:80:393-7.

119. Britton S, Bejstedt M, Vedin L. Chest physiotherapy in primary pneumonia. BMJ 1985:290:1703-4

120. Levine A. Chest physical therapy for children with pneumonia. J Am Ostheopath Assoc 1978;78:22-5.

121. Stapleton T. Chest physiotherapy in primary pneumonia. BMJ 1985;291:143.

122. Paludo C, Zhang L, Lincho CS, et al. Chest physical therapy for children hospitalized with acute pneumonia: a randomized controlled trial. Thorax 2007;63:791-4. 